\title{
ADVANCE AUDIT - PRACTICAL AUDIT TOOL FOR IMPROVING URBAN MOBILITY PLANS
}

This paper presents the methodology and the results of the ADVANCE project. ADVANCE supports cities and municipalities on their way towards a more sustainable urban mobility, thus assisting them to set up and improve the quality of Sustainable Urban Mobility Plans (SUMPS) and policies. ADVANCE has developed an audit scheme designed by an interdisciplinary team of mobility experts, to assess the quality of the cities' mobility plans. Thereby, it contributes to the take-up of Sustainable Urban Mobility Plans in Europe.

Keywords: Audit, assessment, mobility, plan, SUMP.

\section{Introducing ADVANCE and SUMP}

ADVANCE was an international project funded by Intelligent Energy Europe programme, which ran from 2011 to 2014. It aimed to develop, test and apply the ADVANCE Audit - a tool that analyses the strengths and weaknesses in the current sustainable mobility planning of a city and gives clear indications for improvement. Measures and areas of actions to improve the sustainable mobility planning in the city can be derived directly from the action plan that results from the audit process. The action plan can be used as a basis for the development of a new or updated Sustainable Urban Mobility Plan.

Sustainable Urban Mobility Plans (SUMPs) define a set of interrelated measures designed to satisfy the mobility needs of people and businesses today and tomorrow. They are the result of an integrated planning approach and address all modes and forms of transport in cities and their surrounding area. Different approaches to sustainable urban mobility planning exist throughout Europe. While some countries, such as France and the UK, may be considered forerunners, Sustainable Urban Mobility Plans are a new or yet unknown planning tool in other parts of the EU including Slovakia. Sustainable Urban Mobility Plans mean "Planning for People". The European ELTIS plus project has highlighted the benefits of SUMPs in comparison to traditional transport plans. SUMPs take due consideration of integration, participation, and evaluation principles with the aim to create a sustainable urban transport system by addressing - at least - the following objectives:

- Ensure the accessibility offered by the transport system is available to all;

- Improve safety and security;
- Reduce air and noise pollution, greenhouse gas emissions and energy consumption;

- Improve the efficiency and cost-effectiveness of the transportation of persons and goods;

- Contribute to enhancing the attractiveness and quality of the urban environment and urban design.

A Sustainable Urban Mobility Plan is a way of tackling transport-related problems in urban areas more efficiently. Building on existing practices and regulatory frameworks, its basic characteristics are:

- A participatory approach: involving citizens and stakeholders from the outset and throughout the process in decision making, implementation and evaluation, building local capacity for handling complex planning issues;

- A pledge for sustainability: balancing economic development, social equity and environmental quality;

- An integrated approach: mixing practices and policies between policy sectors (e.g. transport, land-use, environment, economic development, social inclusion, gender equity, health, safety), between authority levels (e.g. district, municipality, agglomeration, region, nation, EU), and between neighbouring authorities (inter-municipal, interregional, transnational, etc.);

- A focus on achieving measurable targets derived from short term objectives;

- A review of transport costs and benefits, taking into account wider societal costs and benefits, also across policy sectors.

Based on the methodology developed within the ELTIS plus project, an "ideal" planning cycle for a sustainable urban mobility plans was defined (Fig. 1). The ADVANCE Audit process, which

\footnotetext{
* Dana Sitanyiova, Sona Masarovicova

Department of Geotechnics, Faculty of Civil Engineering, University of Zilina, Slovakia

E-mail: dana.sitanyiova@fstav.uniza.sk
} 


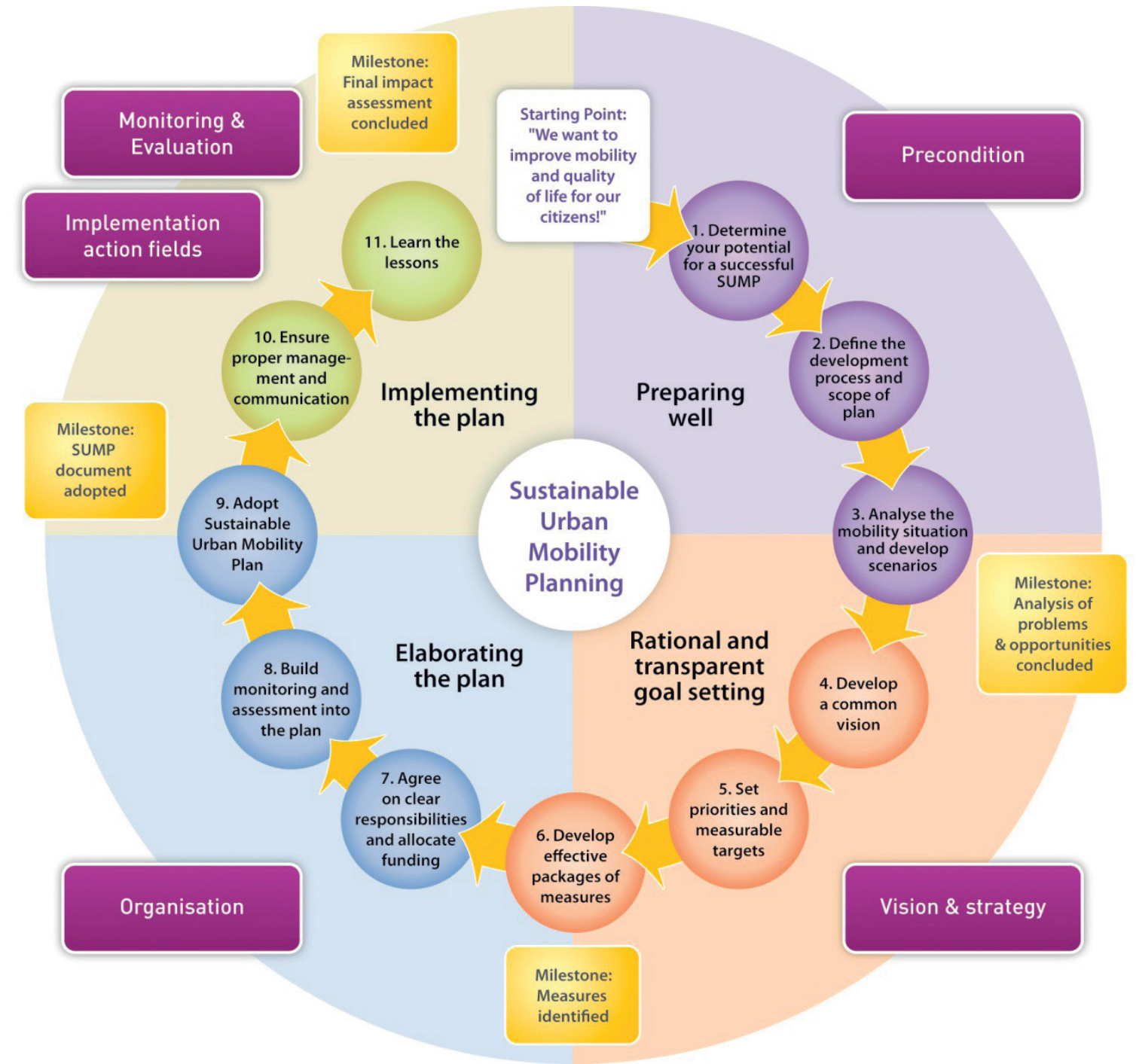

Fig. 1 SUMP cycle in relation to the Mission Fields of ADVANCE

Source: Guidelines SUMP - ELTISplus, 2011 [1]

is based on this SUMP development cycle, distinguishes between 5 Mission Fields, related to the process of setting up a SUMP (Precondition, Vision \& Strategy, Organisation, Implementation of action fields, Monitoring \& Evaluation) and 8 Action Fields related to the implementation of measures defined in a SUMP (Parking management, Street design, Walking, Cycling, Public transport, Car related measures, Mobility management, Freight management) that compose the main elements of a SUMP. The Action fields and Mission Fields are assessment basis for the ADVANCE Audit scheme:

- Action Fields are actions and measures described in a SUMP;

- Mission Fields are related to the process of a SUMP.

\section{Total quality management in sustainable mobility planning}

According to the principles of Total Quality Management, excellent quality is the result of continuous improvement achieved by applying the repetitive cycle of success with a view to fulfil the city's needs [1]. Based on this, ADVANCE considers sustainable mobility planning as a dynamic process that can be depicted with the ADVANCE Audit Scheme (Fig. 2).

There were three categories defined in the project to identify the status of a SUMP and sustainable urban mobility policy in a city:

1. Starting cities: These cities do not have a SUMP or a sustainable mobility strategy at all. The city takes ad hoc 


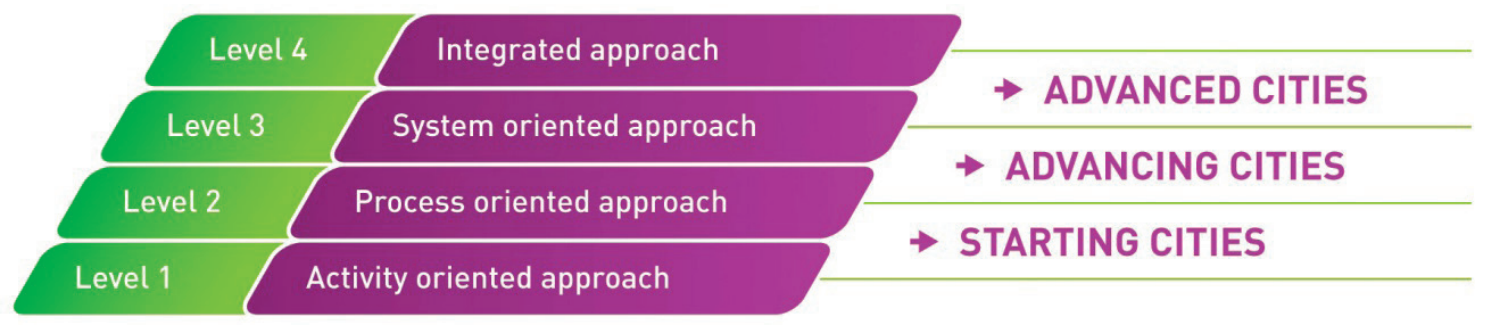

Fig. 2 Quality management ladder of development; Source [2]

measures in case of an urgent mobility problem and will only give short term and purely technical solutions towards mobility problems.

2. Advancing cities: The city has a SUMP and there is a common vision on which mobility strategy to follow. There is a systematic approach towards actual or expected mobility problems. The city takes first steps in evaluating the current mobility policy to find out in which fields improvements are possible.

3. Advanced cities: The city has a SUMP and a clear mobility strategy. The mobility policy is constantly evaluated and quality indicators are being used. The city anticipates expected mobility problems via monitoring. The mobility policy is oriented to the future and innovative solutions are implemented.

The important element to consider is the iterative process of elaboration of a SUMP: the elaboration of a SUMP should not be the summative result of successive stages of studies, but an integrative process allowing a shared diagnosis of the situation, a progressive definition of objectives and the consistency of means.

The ADVANCE Audit can be conducted in small, medium and large sized cities. The size of the partner cities, which tested and applied the ADVANCE Audit, varied from about 35.000 inhabitants (Agioi-Anargyroi, Greece) to more than 400.000 inhabitants (Szczecin, Poland). But the ADVANCE Audit is also suitable for larger cities. The ADVANCE Audit Scheme intends to systemize the mobility planning process by:

- Assessing the city's sustainable urban mobility plan and policy;

- Describing the strengths and weaknesses in the different planning elements;

- Prioritising improvement actions together with relevant stakeholders;

- Editing an ADVANCE action plan which can be a basis for a new or updated SUMP.

The audit scheme has not only the aim to improve the quality of the SUMP as a paperwork of the mobility planning and policy in the city, but it has also the aim to analyse, systemize and improve the whole process of the development of the SUMP (involvement of citizens and stakeholders, presence of a clear vision, collaboration between different departments - urban planning, traffic, etc.). The cities are guided through the auditprocess with the help of a trained ADVANCE Auditor (See www.eu-advance.eu for the list of certified auditors). Cities that pass the ADVANCE Audit successfully receive a certification. Repeating the ADVANCE Audit regularly every 5 years will indicate progress in the sustainable mobility planning of the city.

\section{Audit methodology}

The ADVANCE Audit Scheme is not a theoretical model, but it has already been applied in practice during its development phase. The final ADVANCE Audit Scheme is based on discussions within the consortium (including the University of Zilina), a first test-run in 3 cities, the feedback from the EUROCITIES network, the feedback from the QUEST scientific board and a second-testrun in 6 cities (including Zilina) and 7 Brussels Municipalities. The ADVANCE Audit Scheme guides cities in 5 steps through the audit during a period of maximum 6 months (Fig. 3).

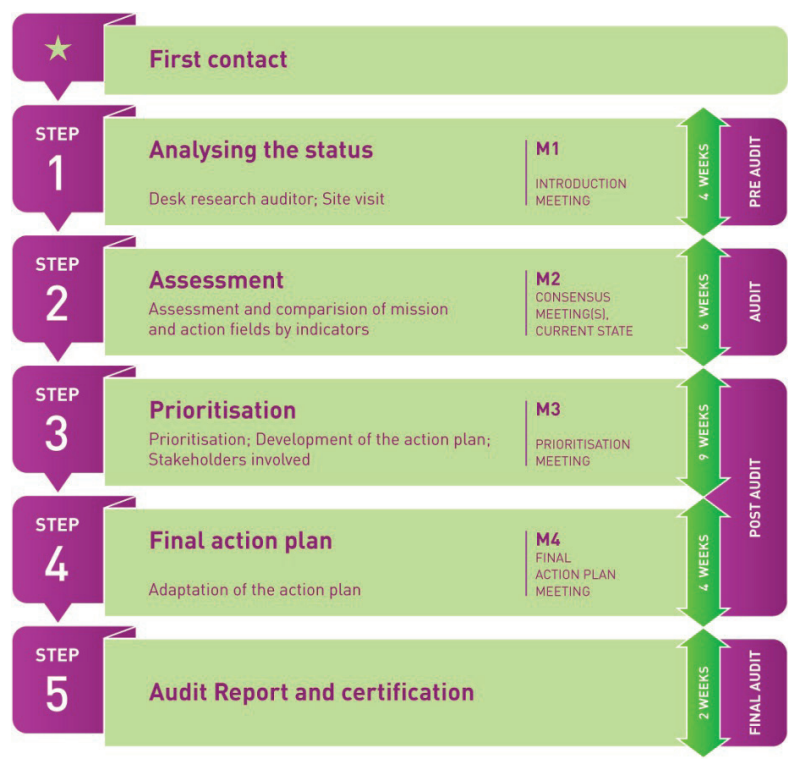

Fig. 3 ADVANCE Audit Scheme Source [2] 


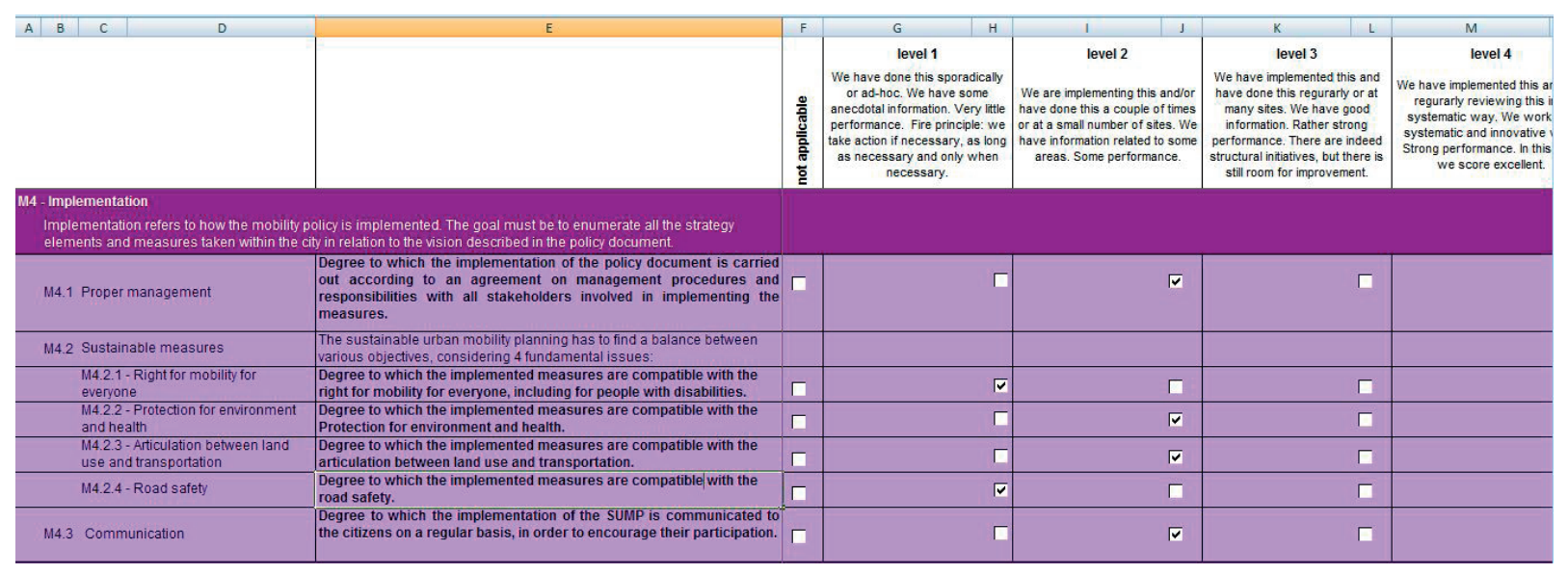

Fig. 4 Assessment of Mission Field - Implementation

\section{Step 1}

A meeting between the auditor and the city is organized. The auditor explains the ADVANCE Audit process including the commitment needed from the city. $\mathrm{He} / \mathrm{she}$ describes the necessary capabilities and resources that are required to compose the ADVANCE working group. Special emphasis is put by the auditor on the involvement of relevant stakeholders. The city and the auditor agree on the definitive composition of the working group. The auditor collects some context indicators that will help the auditor to set up the baseline situation of the city. The context indicators are organized in two main groups. On the one hand, those indicators that will help the auditor set up the baseline situation of the city and, on the other hand, those indicators that will help the auditor to evaluate changes in the local mobility policies. These data are also important to evaluate the effects of the application of the ADVANCE Audit in future. The auditor has to collect these data and include them in the assessment report.

\section{Step 2}

The auditor researches the relevant documents (SUMP, mobility plans, transport plan etc.) and carries out a site visit that can be combined with the first working group meeting where the auditor explains all the details of the ADVANCE Audit process. Special attention is given to the role and expectations towards all participants. The working group needs to be composed of the main internal and external players on urban transport and mobility planning. It is important that the group's composition reflects the departments within the city and the relevant stakeholders that are responsible for the functions covered by the mission and action fields. It is also important to find out about the political level's interest in the ADVANCE Audit before the actual start of the audit process. The auditor distributes the ADVANCE questionnaire which will be used to assess the quality of mobility planning in the city.

\section{ADVANCE questionnaire}

The ADVANCE questionnaire is the main instrument to perform the assessment of the current situation. This assessment is crucial in helping to define appropriate policies and provides the necessary baseline against which progress can be measured. The analysis should be as comprehensive as possible, but also needs to be manageable with the given resources. The ADVANCE evaluation questionnaire covers all the Mission and Action Fields. It is an excel document that provides an interactive tool to score and visualise the results. The Mission Fields and Action Fields are assessed by scoring the statements. All statements are to be assessed on a scale from level 1 to 4 . Level 4 indicates the highest level of performance or implementation and level 1 the lowest (Fig. 4). The ADVANCE working group members complete the ADVANCE questionnaire individually. The scoring for the different mission and action fields is presented using cobweb diagrams. This is illustrated for the Action Fields (Fig. 5).

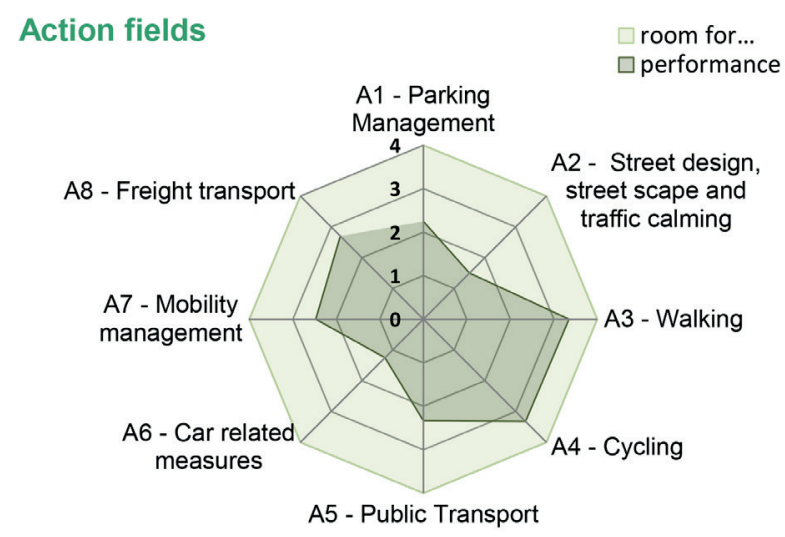

Fig. 5 Cobweb Action Fields

In the example in Fig. 5 the strength of the city lies within the Action Fields A3 and A4. The weakness lies within the Action Fields A2 and A6. The scoring for the individual statements per 


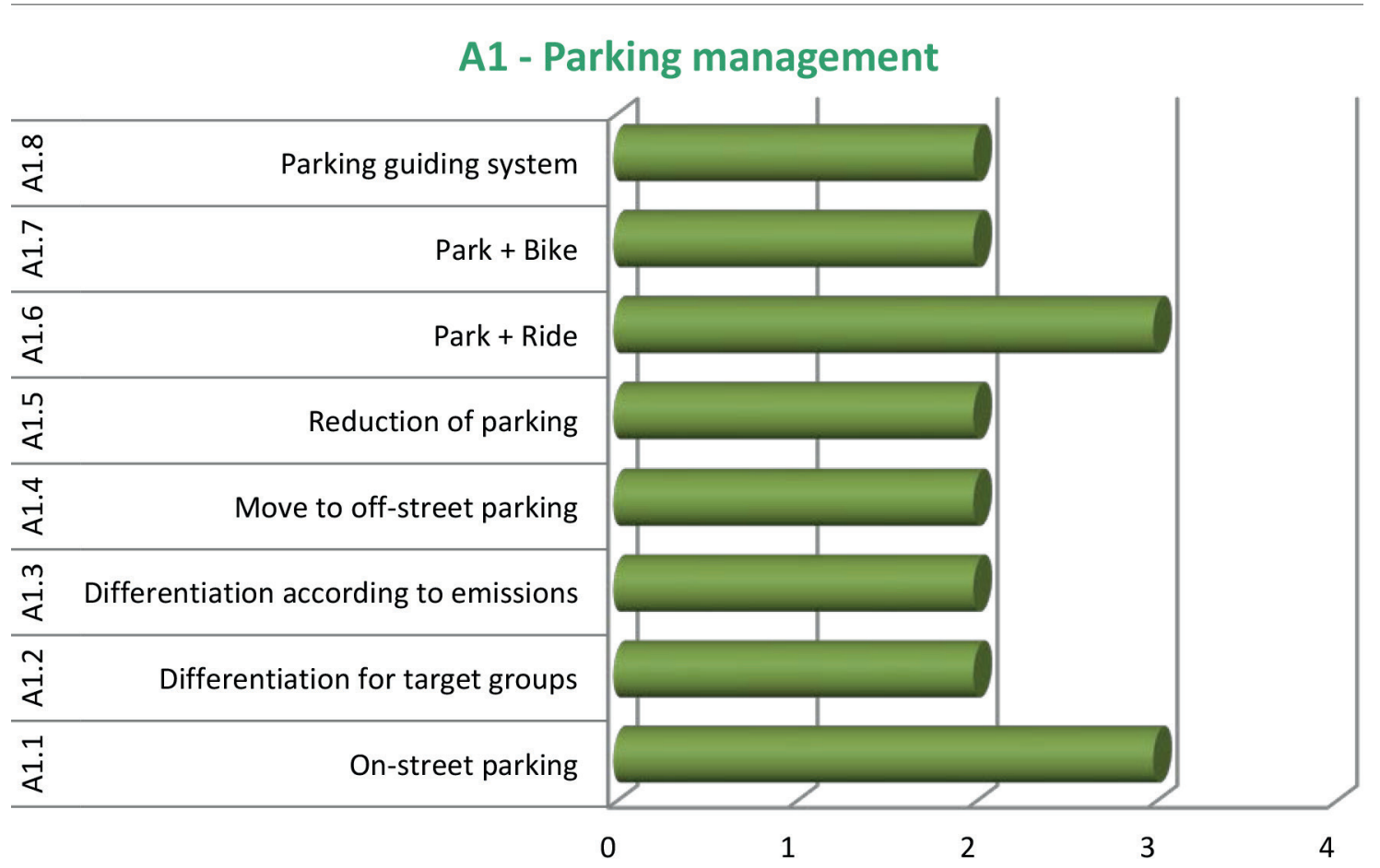

Fig. 6 Bar diagram for Action filed A1 - Parking management

mission and action fields in questionnaire is presented in bar diagrams (Fig. 6 - example for parking management).

All individual questionnaires are collected, summarised and analysed by the auditor with the help of excel summary tool. During the consensus meeting, it is important for the auditor to facilitate the discussion about strengths and weaknesses. At the end of the meeting a consensus on the score for every field has to be reached. Several options to achieve a consensus are available: keeping the arithmetic average, up- or down grading based on arguments of individual group members, voting for average score. The city is evaluated as Advanced if it reaches the total score $>75 \%$, as Advancing if the score is $>50 \%$, and as Starting if it is $<50 \%$.

\section{Step 3}

After the consensus meeting all members of the working group representing different organisations, stakeholders and municipality are asked to compile their list of priorities. The auditor drafts an action plan (AP) based on the list of possible improvement actions. In the AP concrete objectives and actions are set out in a timetable with specific budgets and responsible persons or departments. During prioritisation meeting a discussion takes place on the priorities in the list of actions mentioned in the draft AP. The discussion is done in a plenary session or in different working groups. The working group discusses and agrees on which (other) stakeholders need to be consulted before drawing the final AP.

\section{Step 4}

Based on the previous steps the final ADVANCE Action Plan is edited by the auditor. This is a final output of the ADVANCE Audit process with concrete actions to improve the local urban mobility plan and policy. The AP needs to reflect the commitment of the key actors and implementation actors and will be presented to the political representatives of the city. In order to apply for the ADVANCE-certificate the AP needs to be accepted by the political decision takers. The AP is no SUMP in itself, but can be the basis for the development (in starting cities without a SUMP) or the upgrade (in advancing or advanced cities) of the local SUMP. While the time horizon for the implementation of a whole SUMP might take more than five years, the proposed actions in the AP should be able to get implemented within the next five 5 years.

\section{Step 5}

The auditor writes the Audit Report including the notes of the working group meetings and recommendation for certification. The final and approved AP is added as an annex to the Audit Report. If the city meets the criteria for certification, it receives the ADVANCE certificate. 


\section{Conclusions}

The progress of the implementation of the Action Plan is checked by the ADVANCE Committee after a period of 3 years based on an update of the Action Plan. The city is informed about the time of the Action Plan update. The ADVANCE certificate must be confirmed every 5 years by the ADVANCE Committee. A city can do a re-audit if it meets the following procedural steps: - The City has sent a follow-up of the Action Plan after a 3 years period to the ADVANCE Secretariat;

- The City has fulfilled at least $50 \%$ of the actions during the time-frame of the certificate since it was certified.

For the re-audit the audit and the certification process will be similar to the initial certification. This approach ensures the sustainability of actions to improve the Sustainable Urban Mobility in the city.

ADVANCE project developed a methodology for multicriterion evaluation. The audit provides an honest and clear picture on the strengths, weaknesses and opportunities of current planning practices with regard to developing a Sustainable Urban Mobility Plan in the local context. The evaluation methodology is very efficient for obtaining conclusions in a minimum period of time. The crucial aspect of the methodology is involvement of all different types of stakeholders throughout the planning process, addressing their specific requirements. There were different approaches to assess the quality of a city's entire sustainable mobility policy being developed in the three IEE STEER projects: Ecomobility SHIFT (www.ecomobility.org/shift/), QUEST (www.quest-project.eu/) and ADVANCE (eu-advance. eu/). Final ADVANCE Audit Scheme and Guidelines with comprehensive description of the methodology and the whole audit process is available at: http://eu-advance.eu/docs/file/ d2_5_final_advance_audit_scheme_including_guidelines_en.pdf. European Commission should decide for common procedure to assess the quality of SUMPs in near future.

\section{Legal disclaimer}

The sole responsibility for the content of this paper lies with the authors. It does not necessarily reflect the opinion of the European Union. Neither the EACI nor the European Commission is responsible for any use that may be made of the information contained therein.

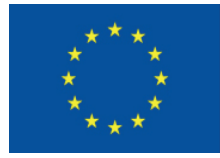

Co-funded by the Intelligent Energy Europe Programme of the European Union

\section{References}

[1] Mobilityplans.eu: Guidelines on the development and implementation of a Sustainable Urban Mobility Plan (online http://www. mobilityplans.eu/docs/file/guidelines-developing-and-implementing-a-sump_final_web_jan2014b.pdf).

[2] ADVANCE consortium: Final ADVANCE Audit Scheme and Guidelines, 2014. 